\title{
KESIAPAN DAN PERSEPSI MAHASISWA KEPERAWATAN PADA PROGRAM IPE : STUDI PADA SGD DENGAN LBM JIWA
}

\author{
Betie Febriana $^{1}$ \\ ${ }^{1}$ Fakultas Ilmu Keperawatan, Universitas Islam Sultan Agung \\ betie.febriana@gmail.com
}

\begin{abstract}
ABSTRAK
Pengenalan kolaborasi antar professional kesehatan penting dilakukan sejak dini melalui pendidikan dengan model interprofessional education (IPE). Beberapa studi melaporkan, hal lain yang mempengaruhi kolaborasi tersebut adalah self-efficacy dari mahasiswa. Untuk membentuk self efficacy yang baik diperlukan kajian mengenai kesiapan dan persepsi mahasiswa terkait metode pembelajaran IPE di unissula. Pendekatan penelitian kuantitatif dengan jenis deskriptif noneksperimental dan rancangan cross sectional. Sampel penelitian adalah 100 mahasiswa menggunakan purposive sample yaitu mahasiswa yang telah mengikuti SGD LBM Jiwa dengan lengkap. Alat ukur menggunakan kuisioner SPICES untuk mengukur persepsi dan RIPLS untuk kesiapan. Analisa univariat menggunakan distribusi frekuensi untuk tingkat persepsi dan kesiapan IPE dengan skala ordinal. Studi ini menemukan bahwa $84 \%$ persepsi mahasiswa keperawatan terhadap IPE adalah baik dan mahasiswa $85 \%$ berada dalam kondisi siap pada tahap akademik. Baiknya, dilakukan pengukuran dan pembandingan persepsi dan kesiapan antar mahasiswa lintas profesi untuk memformulasikan konsep yang baik demi tercapainya tujuan IPE.
\end{abstract}

Kata kunci: Interprofessional education, persepsi, kesiapan ,small group discussion.

\section{EARLY INTRODUCTION OF COLLABORATION BETWEEN HEALTH PROFESSIONALS IS IMPORTANT THING. IT COULD BE DONE THROUGH INTERPROFESSIONAL EDUCATION (IPE) MODELS}

\begin{abstract}
Early introduction of collaboration between health professionals is important. It could be done through education with interprofessional education (IPE) models. Several studies report, another thing that affects the collaboration is student self-efficacy. To form a good self efficacy, study of the readiness and perception of students related to the IPE learning method is needed to know before. This researches was Quantitative research approach with descriptive non-experimental type and cross sectional design. The research sample was 100 students using random technique samples, students who had attended the SGD LBM mental health completely. The instrument used the SPICES questionnaire fot perceptions and RIPLS for readiness. Analysis used univariate with frequency distribution for the level of perception and readiness of IPE. This study found that $84 \%$ of nursing students' perceptions of IPE were good and $85 \%$ students were in a condition ready at the academic stage. It is better to measure and compare perceptions and readiness between cross-professional students to formulate good concepts to achieve the objectives of IPE.
\end{abstract}

Keywords: Interprofessional education, persepsi, kesiapan ,small group discussion.

\section{PENDAHULUAN}

Tuntutan pelayanan kesehatan yang berkualitas semakin meningkat seiring bertambahnya kesadaran masyarakat tentang kesehatan. Salah satu upaya untuk mewujudkan kolaborasi antartenaga kesehatan adalah dengan memperkenalkan sejak dini praktik kolaborasi melalui proses pendidikan. Interprofessional Education (IPE) telah menjadi isu penting sebagai sebuah inovasi yang sedang dieksplorasi dalam dunia pendidikan profesi kesehatan saat ini.

IPE merupakan metode pembelajaran yang terjadi ketika dua atau lebih profesi belajar dengan, dari dan tentang satu sama lain untuk meningkatkan kerjasama dan hasil kesehatan. Program ini merupakan salah satu program 
yang diusulkan oleh Ditjen Pendidikan Tinggi (DIKTI). Perawat merupakan tenaga medis terbesar di Indonesia (Depkes, 2017). Oleh karena itu, tenaga keperawatan mempunyai kontribusi besar dalam pemberian pelayanan kesehatan.

Panel Ahli Kolaborasi Interprofessional (IPEC) mengidentifikasi self-efficacy dan kompetensi budaya sebagai kompetensi mendasar dalam domain inti IPE dan praktek kolaboratif (IPEC, 2016). Studi lain telah mengeksplorasi self-efficacy dan hasil perawatan pasien (Dahl \& Hall, 2013) bahwa hal ini diperlukan untuk memberikan pelayanan yang baik pada pasien. Penelitian sebelumnya melaporkan cara-cara untuk meningkatkan self-efficacy di antara para profesional perawatan kesehatan melalui pelatihan komunikasi (Norgaard, dkk., 2012) dan pembelajaran berbasis masalah (Darkwah, dkk. 2011). Selanjutnya, penelitian lain menunjukkan bahwa ada perubahan dalam self-efficacy (Coogle, dkk. 2016), dan kompetensi budaya (Oliveira, dkk. 2015) terjadi dengan keikutsertaan mahasiswa dalam kegiatan IPE.

Dalam penelitian Margolish (2014) ditemukan bahwa siswa perawat yang memiliki self efficacy rendah cendrung memiliki harga diri yang rendah saat di klinik dan meungkinkan mereka untuk meninggalkan profesi sebagai perawat. Self-efficacy merupakan salah satu hal yang penting dari IPE baik sebagai outpun maupun proses saat IPC (interprofessional Collaboration) di clinik atau dunia kerja. Self efficacy akan muncul dan terbentuk dari persiapan dan persepsi yang baik dari sumber daya yang bersangkutan, sehingga penting untuk mengetahui dan membentuk persepsi demi kelancaran metode pembelajaran ini.

Salah satu universitas di Semarang dalam hal ini fakutas rumpun kesehatan yaitu kedokteran, keperawatan, dan farmasi telah mencoba IPE sebagai metode pembelajaran. Mata kuliah yang dipakai adalah Jiwa dalam metode small group discussion. Dua LBM dari mata kuliah tersebut didiskusikan bersama oleh mahasiswa tiga jurusan tersebut. Hal ini merupakan langkah awal penerapan IPE akademik. Hasil wawancara pada beberapa mahasiswa keperawatan mereka menyatakan terkejut saat tahu akan di-IPE-kan dan menyatakan harus belajar lebih agar bisa kondusif saat diskusi, beberapa dianataranya percaya diri dan beberapa pula merasa takut terutama mahasiswa yang tidak terlalu cakap dalam berdiskusi, mengingat ini adalah diskusi antara tiga profsi yang berbeda. Oleh karena itu penting untuk dilakukan penelitian mengenai persepsi mahasiswa tentang metode pembelajaan IPE dan kesiapan mereka menghadapinya.

\section{METODE}

Penelitian ini menggunakan pendekatan kuantitatif dengan jenis deskriptif noneksperimental dan rancangan cross sectional dengan pengumpulan data melalui kuesioner yaitu pengukuran persepspsi dengan Student Perceptions of Physician-Pharmacist Interprofessional Clinical Education (SPICE) instrument. Sedangkan kesiapan dengan Readiness for Interprofessional Learning Scale (RIPLS) Questionnaire. Pengolahan data menggunakan data distribusi frekuensi. Populasi penelitian ini adalah mahasiswa keperawatan Unissula yang telah mengikuti dengan sempurna SGD LBM Jiwa yaitu sejumlah 100 orang dengan random sampling dimana sebelumnya mereka telah dibekali dengan pengantar IPE .

\section{HASIL}

Berdasarkan tabel 1 diketahui bahwa responden lebih banyak perempuan berusia 20 tahun dan laki-laki hanya $7 \%$ dari total resonden. Menurut tabel 2 terbaca bahwa persepsi mahasiswa sebagian besar hampir terkategori baik sebesar $84 \%$, kemudian sedang $12 \%$ dan hanya 4 mahasiswa yang berpersepsi kurang. Dari tabel 3 kita dapat melihat bahwa mahasiswa keperawatan sebagian besar ada dalam kondisi siap dalam menempuh proses pembelajaran model IPE dalam tahap akademik yaitu sebesar $85 \%$, dan sisanya merasa kurang siap. 
Tabel 1.

Karakteristik Responden ( $\mathrm{n}=100)$

\begin{tabular}{lll}
\hline \multicolumn{1}{c}{ Karakteristik } & $\mathrm{f}$ & $\%$ \\
\hline Jenis Kelamin & & \\
Laki-laki & 7 & 7 \\
Perempuan & 93 & 93 \\
\hline Usia & & \\
19 & 27 & 27 \\
20 & 64 & 64 \\
21 & 9 & 9 \\
\hline
\end{tabular}

Tabel 2.

Persepsi mahasiswa keperawatan terkait pembelajaran IPE $(\mathrm{n}=100)$

\begin{tabular}{lll}
\hline Kategori & $\mathrm{f}$ & $\%$ \\
\hline Kurang & 4 & 4 \\
Sedang & 12 & 12 \\
Baik & 84 & 84 \\
\hline
\end{tabular}

Tabel 3.

Kesiapan Mahasiswa Keperawatan terkait IPE $(\mathrm{n}=100)$

\begin{tabular}{lll}
\hline Kategori & f & $\%$ \\
\hline Kurang & 15 & 15 \\
Siap & 85 & 85 \\
\hline
\end{tabular}

\section{PEMBAHASAN}

Dalam penelitian ini adalah benar bahwa lakilaki jauh lebih sedikit dibandingkan wanita karena factor jumlah mahasiswa yang lebih banyak perempuan tetapi, temuan dari beberapa penelitian sebelumnya (Talwalkar dkk 2016; Wilhelmsson dkk, 2011) mahasiswa perempuan menunjukkan sikap yang lebih positif terhadap IPE daripada teman sekelas laki-laki mereka. Coster dkk (2008) menyoroti perbedaan dalam gaya belajar antara jenis kelamin yang mungkin menyebabkan perempuan lebih mudah menerima IPE. . Secara khusus, wanita cenderung menekankan mendengarkan, memahami, dan memercayai pandangan orang lain saat belajar. Namun, gender tidak secara konsisten dikaitkan dengan perbedaan kesiapan individu.

Berdasarkan hasil penelitian, didapatkan data bahwa bahwa persepsi mahasiswa sebagian besar hampir terkategori baik sebesar $84 \%$, kemudian sedang $12 \%$ dan hanya 4 mahasiswa yang berpersepsi kurang. Artinya di lingkungan keperawatan sendiri notabene poin of view mahasiswa keperawatan terhadap program pembelajaran interprofessional education baik dengan kata lain mereka meletakkan harapan dari proses pembelajaran ini.
Model pembelajaran ini memang dibuat agar terjadi kolaborasi lebih awal anatara profesi kesehatan yang satu dan yang lain untuk membuat mereka saling memahami akan keberadaan profesi yang lain. Selain itu, program ini juga untuk menciptakan team work yang solid yang akan berimplikasi pada percepatan proses kesembuhan pasien, baik secara kualitas ataupun kuantitas. Hal lain yang ingin dicapai adalah bahwa ada kolaborasi yang baik antar mereka di lahan klinis sehingga mengurangi miskomunikasi serta malpraktek.

Persepsi baik sedemikian besar ini dapat menjadi modal awal yang baik mahasiswa untuk mengikuti tahap pembelajaran akademik. Karena persepsi sangat berpengaruh pada motivasi mahasiswa entah untuk belajar ataupun keingintahuan yang besar. Dimulai dari persepsi, seorang individu akan menetapkan apa yang ingin dia lakukan. Studi oleh Pohancova (2010) menggambarkan bahwa motivasi mempunyai hubungan dengan kemampuan mengambil keputusan. Selaras dengan penelitian lain (Nasiyati ,2014) menyatakan bahwa kemampuan mengambil keputusan akan meningkat seiring dengan motivasi yang tinggi. 
Persepsi mahasiswa yang tinggi ini juga dapat dipengaruhi oleh interaksi mereka sebelumnya yang telah menempuh pendidikan klinik, walaupun IPE belum didapatkan dari proses klinik sebelumnya, tetapi mereka dapat menerka dan membaca bagaimana antar profesi kesehatan saling berkolaborasi sehingga terdapat daya analisis pada masingmasing individu yang pada akhirnya menghasilkan persepsi yang baik akan IPE.

Selain itu, beberapa pengajar di Fakultas Ilmu Keperawatan adalah profesi lain seperti dokter, apoteker, dan terapis bahkan profesi religius. Keberadaan mereka dapat membantu membuat persepsi yang baik akan pembelajaran ini. Temuan ini berbeda dengan studi Acquavita dkk (2014) yaitu hambatan pribadi yang diidentifikasi dalam persepsi pada pembelajaran ini adalah tidak dapat menerima pembelajaran dari profesional lain, secara pribadi memiliki stereotip dan persepsi salah tentang profesi lain dan profesisentralisme.

Faktor lain dari hasil observasi bahwa sebelumnya telah dipaparkan konsep IPE baik tujuan dan kebaikannya sehingga hal ini mempengaruhi persepsi mahasiswa. Menurut Lee (2009) dosen maupun staff mengajar menjadi salah satu faktor pembentuk kesiapan mahasiswa dalam penerapan IPE. Menurut Barr (2003), dorongan positif dari institusi penyelenggara sangat berperan dalam pendukung pelaksanaan IPE. Data memperlihatkan bahwa mahasiswa secara umum ada dalam kondisi siap pada program belajar ini. Sebuah temuan yang mirip dengan yang dilaporkan dalam studi dari Kanada, 14 Selandia Baru, 15 dan Swedia21 bahwa mahasiswa keperawatan memiliki kesiapan yang tinggi (Curran, dkk, 2008; Horsburgh dkk, 2006; Talwalkar dkk, 2016; Wilhelmsson dkk, 2011). Studi oleh Horsburgh dkk (2006) yang juga membandingkan antara mahasiswa keperawatan dan kedokteran menemukan bahwa mahasiswa keperawatan lebih baik dalam berpikir kolaboratif berbeda dengan mahasiswa kedokteran yang berpikir individualistis.

Kesiapan mahasiswa, peneliti yakini berhubungan dengan persepsi mengenai pembelajaran ini. Penelitian yang dilakukan oleh Yuniawan A (2015) bahwa kesiapan terhadap IPE justru mempunyai hubungan dengan persepsi terhadap IPE. Hal ini dapat terjadi karena adanya persamaan komponen diantara kesiapan IPE dan persepsi IPE, yaitu komponen bukti bekerja sama dengan teamwork dan kolaborasi. Salah satu outcome yang diharapkan dalam penerapan IPE adalah terjadinya teamwork dan kolaborasi yang kuat antar professional kesehatan dari disiplin ilmu yang berbeda. Sesuai dengan konsep kesiapan Parsell and Bligh (1999) yang dirangkum dalam RIPLS, komponen kesiapan terhadap IPE ada tiga hal penting, yaitu identitas masing-masing profesi, Teamwork, dan peran dan tanggung jawab. Berdasarkan hal tersebut mahasiswa keperawatan pada lokus tersebut dapat dinyatakan bahwa kesiapannya baik entah dari tema work, peran dan tanggung jawab.

\section{SIMPULAN DAN SARAN \\ Simpulan}

Penelitian ini berusaha mengidentifikasi faktor-faktor yang terkait dengan masingmasing dari 3 jenis perilaku saksi (membela, diam, dan ikut serta membully) pada remaja di sekolah berasrama. Jenis kelamin dan usia merupakan variabel yang berpengaruh dan memiliki korelasi sedang terhadap perilaku saksi. Dua factor tersebut hanya mempengaruhi $27 \%$ dari semua factor yang ada.

\section{Saran}

Pihak sekolah perlu memaksimalkan fungsi badan konseling atau pembentukan klinik jiwa remaja seperti UKS. Mengoptimalkan fungsi supervisor asrama dan nilai-niai agama untk mencegah kasus bullying. Dibutuhkan penelitian lebih lanjut tentang factor lain terkait perilaku saksi saat dihadapkan dengan bullying karena temuan studi hanya $27 \%$ yang sisanya dipengaruhi factor lain selain usia dan jenis kelamin.

\section{DAFTAR PUSTAKA}

Acquavita SP, Lewis MA, Aparicio E, Pecukonis E. (2014). Student perspectives on interprofessional education experiences. $J$ Allied Health; 43(2): e31-6. 
Ahmad MI, Chan SW, Wong LL, Tan ML, Liaw SY. (2013). Are first-year healthcare undergraduates at an Asian university ready for interprofessional education? J Interprof Care. 27:341343.

doi:

10.3109/13561820.2013.769094. [PubM ed] [CrossRef]

Alavi, A, Bahrami, M, Boroujeni, A.Z, Yousefi, A. (2015). Pediatric nurses perception of factors associated with caring self efficacy. Iran $\mathbf{J}$ nurs Midwifery Res. 20(2). 232-238.

Bandura, A (2010). Self Efficacy Mechanism in Psikological and Health Promoting Behavior, Prentice Hall, New Jersy.

Barr, H., (2003). Undergraduate Interprofessional Education. Education Committee Discussion Document. Available URL: www.caipe.org.uk

Coogle, C. L., Hackett, L., Owens, M. G., Ansello, E. F., \& Mathews, J. H. (2016). Perceived self-efficacy gains following an interprofessional faculty development programme in geriatrics education. Journal of Interprofessional Care, 30(4), 483-492.Doi:

$\underline{10.1080 / 13561820.2016 .1177003}$

Coster S, Norman I, Murrells T, Kitchen S, Meerabeau E, Sooboodoo E, d'Avray L. (2008) Interprofessional attitudes amongst undergraduate students in the health professions: a longitudinal questionnaire survey. Int $\mathrm{J}$ Nurs Stud. 45:1667-1681.doi:

10.1016/j.jinurstu.2008.02.008.

Curran VR, Sharpe D, Forristall J, Flynn K. (2008). Attitudes of health sciences students towards interprofessional teamwork and education.7:146-156. doi:10.1111/j.1473 6861.2008.00184.x.

Handayani. (2017). Hubungan antara self efficacy dengan kinerja perawat dalam melaksanakan askep di igd dan isu-issu RSUD sragen. http://digilib.stikeskusumahusada.ac.id
Horsburgh M, Perkins R, Coyle B, Degeling P. (2006) The professional subcultures of students entering medicine, nursing and pharmacy programmes. J Interprof Care. 20:425-431. doi: $10.1080 / 13561820600805233$.

Interprofessional Education Collaborative. (2016). Core competencies for interprofessional collaborative practice: 2016 update. Washington, DC: Interprofessional Education Collaborative. Available from:http://www.aacn.nche.edu/educatio n-resources/IPEC-2016-Updated-CoreCompetencies-Report.pdf

Lee TW, Ko YK. (2010). Effects of selfefficacy, affectivity and collective efficacy on nursing performance of hospital nurses. $J$ Adv Nurs.;66(4):83948. doi: $10.1111 / \mathrm{j} .1365-$ 2648.2009.05244

Darkwah, V., Ross, C., Williams, B., \& Madill, H. (2011). Undergraduate nursing student's self-efficacy in patient education in a context-based learning program. Journal of Nursing Education, 50(10), 570-582.

1. Depkes. (2017). infodatin perawat 2017.pdf - Kemenkes.

www.depkes.go.id/resources/download/ pusdatin/.../infodatin\%20perawat $\% 2020$ 17.pdf

Freeth D (2002) A Critical Review of Evaluations of Interprofessional Education Learning and Teaching Support Network for Health Sciences and Practice London Freeth,

Freeth D ., Reeves, S., (2004). Learning to work together: using the presage, process, product (3P) model to highlight decisions and possibilities. Journal of Interprofessional Care.

Lee, R. (2009). Interprofessional Education: Principles and Application. Pharmacotherapy [Serial online] [cited 2009 June 29] : 29 (3); 145e-164e. Available from: URL :HTTP://www.accp.com 
Margolis H, McCabe P. (2014). Self-Efficacy: A Key to Improving the Motivation of Struggling Learners.Clearing House. ;77(6):241-9. doi: 10.3200/tchs.77.6.241-249.

Masoudi Alavi, N. (2014). Self-Efficacy in Nursing Students. Nursing and Midwifery Studies, 3(4), e25881.

Nasiyati, N. (2014). Hubungan Antara Motivasi Berprestasi Dan Regulasi Diri Dengan Kemampuan Mengambil Keputusan. Indonesian Journal og Guidance and Counselinh Theory and Application. Semarang : Universitas Negeri Semarang

Niu, Y . (2010). "Research on the education strategy," Proc. - 2010 3rd IEEE Int. Conf. Comput. Sci. Inf.. ICCSIT, vol. 6, pp. 177-181, 2010.

Nørgaard, B., Ammentorp,J., Kyvik, PoulErik. (2012). Communication skills training increases self-efficacy of health care professionals. J Contin Educ Health Prof 32(2):9097. doi: 10.1002/chp.2113 1.

Oliveira, K. D., North, S., Beck, B., \& Hopp, J. (2015). Promoting collaboration and cultural competence for physician assistant and physical therapist students: a cross-cultural decentralized interprofessional education model. Journal of Educational Evaluation for Health Professions, 12, 20.

Wilhelmsson M, Ponzer S, Dahlgren LO, Timpka T, Faresjö T. (2011) Are female students in general and nursing students more ready for teamwork and interprofessional collaboration in healthcare? BMC Med Educ. 11:15. doi: 10.1186/1472-6920-11-15.

Yuniawan, A. (2015). Persepsi dan Kesiapan Dosen Terhadap Pembelajaran Interprofesional. Jurnal Keperawatan Soedirman, 10 (2).

Zhang, C., Thompson, S., Miller, C, M., (2011). A Review of Simulation-Based Interprofessional Education. Clinical Simulation in Nursing. Vol 7, e117e126.

Santrock, J. W. (2013). Life-span Development 14th ed. New York: McGraw-Hill Companies, Inc.

Sedyowinarso, M., Fauziah, F. A., Aryakhiyati, N., Julica, M. P., Sulistyowati, E., Masriati, F. N., Olam, S. J., Dini, C., Afifah, M., Meisudi, R., \& Piscesa, S. (2011). Persepsi dan kesiapan mahasiswa dan dosen profesi kesehatan terhadap model pembelajaran pendidikan interprofesi. Proyek HPEQDikti.

Smith L, Perry M, Yorke A. (2017). Does Interprofessional Education Influence Self-Efficacy and Cultural Competence in Pre-Clinical Doctor of Physical Therapy Students? , MedEdPublish. 6, [2], 7,. Doi: 10.15694/mep.2017.000069

Talwalkar, J. S., Fahs, D. B., Kayingo, G., Wong, R., Jeon, S., \& Honan, L. (2016). Readiness for interprofessional learning among healthcare professional students. International journal of medical education, 7, 144-8. doi:10.5116/ijme.570d.7bd8 